\title{
Analgesic Effectiveness of Ultrasound-Guided Pecs II Block in Central Venous Port Catheter Implantation
}

This article was published in the following Dove Press journal: Journal of Pain Research

\author{
Mehmet Emin Ince $\mathbb{D}^{1}$ \\ Ender Sir (D) ${ }^{2}$ \\ Sami Eksert (D) \\ Nadide Ors' \\ Gokhan Ozkan' \\ 'Department of Anesthesiology and \\ Reanimation, Gulhane Training and \\ Research Hospital, University of Health \\ Sciences, Ankara, Turkey; ${ }^{2}$ Department \\ of Algology and Pain Medicine, Gulhane \\ Training and Research Hospital, \\ University of Health Sciences, Ankara, \\ Turkey
}

Background and Aim: In oncology patients, central venous port catheter (CVPC) implantation is generally preferred for venous route. However, in this procedure, postoperative pain is often observed. This study aimed to investigate the effectiveness of ultrasound-guided Pecs II block in the management of pain after CVPC placement.

Methods: One hundred and eighty-seven patients who underwent CVPC implantation between January 2017 and August 2018 were included in the study. Patients who underwent Pecs II block under ultrasound guidance were called as the Pecs group, and those who underwent local anesthesia (LA) were referred as the LA group. All procedural parameters were analyzed, including demographic characteristics of patients, visual analogue scores (VAS) at 2nd and 24th hours, and postoperative opioid, and non-steroidal anti-inflammatory drug (NSAID) consumption.

Results: The postoperative 2nd hour VAS scores were similar in both groups and were lower than the 24th hour VAS scores. VAS scores at the 24th hour in the Pecs group were significantly lower than the LA group $(\mathrm{P}=0.001)$. While the number of fentanyl rescue doses administered in PACU was similar, the total NSAID consumption in the first 24 hours was higher in the LA group than in the Pecs group.

Conclusion: In CVPC placement, ultrasound-guided Pecs II block is a more reliable, easily applicable and longer-acting approach than LA infiltration for postoperative analgesia.

Keywords: analgesia, pain, postoperative, vascular access devices, anesthesia, local, nerve block, thoracic nerves

\section{Introduction}

The prevalence of cancer increases in the community due to increased survival and exposure to carcinogens. There are many treatment methods such as radiotherapy, chemotherapy, and surgery in different types of cancer. However, systemic chemotherapy is the most commonly used and is usually administered as cures at periodic intervals. In order to apply chemotherapeutic agents and supportive therapies, repeated vascular access is required in cancer patients. Therefore, a central venous port catheter (CVPC) is frequently used in oncology patients, in order not to traumatize the patient, both physically and psychologically. CVPC insertion was performed under sedation and local anesthesia (LA) for many years due to prevent anxiety caused by the procedure and provide pain management. The analgesic effect of LA applied to the incision area usually ends after a few hours and most of the patients complain of pain in the area where the catheter is inserted, which usually lasts for several days. ${ }^{1}$
Correspondence: Gokhan Ozkan Department of Anesthesiology and Reanimation, Gulhane Training and Research Hospital, University of Health Sciences, Ankara 06010, Turkey Tel +905325616974

Email dr.gozkan@gmail.com 
In recent years, ultrasound-guided thoracic wall nerve blocks such as pectoralis nerve blocks (Pecs I and Pecs II) have offered an alternative mode of analgesia. ${ }^{2,3}$ When applying the Pecs I block, the needle is advanced to the interfascial plane between the pectoral major and minor muscles, and the local anesthetic solution is applied. ${ }^{4}$ In the Pecs II block defined by Blanco, two needles are used instead of one, and in addition to the Pecs I block, a second injection is applied to the fascial plane between the serratus and pectoralis minor muscle. ${ }^{5}$ While Pecs I block targets only the lateral and medial pectoral nerves, Pecs II block additionally aims to anesthetize the long thoracic nerve and the lateral branches of intercostal nerves between the pectoralis minor and serratus anterior muscle. These blocks provide adequate analgesia in the upper anterior chest wall in the early postoperative period after chest surgery and pacemaker implantation. ${ }^{4,6}$ Considering these, we applied the ultrasound-guided Pecs II block to the Pecs group since we predicted that this would be an effective postoperative analgesia method in CVPC implantation.

Most of the articles about the use of CVPCs are about insertion technique or procedural complications. However, pain caused after catheter placement is mostly ignored. In this study, the efficacy of ultrasound-guided Pecs II block in post-procedure pain management was investigated in patients undergoing CVPC implantation.

\section{Methods}

The current study included 187 patients who underwent CVPC insertion between January 2017 and August 2018. Ethical approval was obtained from the University of Health Sciences Ethical Committee (2019/04-46418926) and the study was conducted in accordance with the Declaration of Helsinki. Before the implantation, all patients were informed in detail about the procedure, and written consent was obtained. Patients over 18 years-old who underwent right subclavian CVPC implantation for the first time were included in the study. Patients who underwent Pecs block were grouped in the Pecs group, and those who had only local anesthetic were grouped in the LA group. Patients with previous catheterization and missing follow-up data were excluded from the study. All patient data were obtained from the patient files and follow-up forms.

CVPC implantation was performed under sedation in the operating room, under strict aseptic conditions using LA infiltration or ultrasound-guided Pecs II block. The patients were followed up with 3-lead electrocardiography, pulse oximetry for hemoglobin oxygen saturation, and noninvasive arterial blood pressure. After preoperative skin preparation, patients underwent sedo-analgesia with bolus dose of midazolam $(0.03 \mathrm{mg} / \mathrm{kg})$, and infusion of remifentanil $(0.05-0.15 \mathrm{mcg} / \mathrm{kg} / \mathrm{min})$. During the procedure, all patients received oxygen (4-6 L/min) $\mathrm{O}_{2}$ with a face mask. All CVPC implantations were performed by an anesthesiologist experienced in percutaneous central vascular catheterization procedures.

The patients were divided into two groups: ultrasoundguided Pecs II block applied ones assigned to the Pecs group, and LA infiltration applied ones assigned to the LA group.

\section{Pecs Group}

Ultrasound-guided Pecs II block was performed on the right side of the chest wall. The patient was placed in a supine position with the right arm abducted. Following aseptic preparation of the skin with chlorhexidine, a high-frequency linear ultrasound probe was placed at midline of the infraclavicular region to identify the pectoralis muscles superficial to the 3rd rib (Figure 1). When the pectoral branch of the thoracoacromial artery was seen, a 22-G 50-mm echogenic needle (Echoplex ${ }^{\circledR}$, Vygon, Ecouen, France) was inserted into the fascial plane between the pectoralis major and minor muscles with an in-plane technique and $10 \mathrm{~mL}$ of $0.25 \%$ bupivacaine was injected (Figure $2 \mathrm{~A}$ and $\mathrm{B}$ ). Then, the needle was advanced further until it lay in the potential space between pectoralis minor and serratus anterior muscles and $15 \mathrm{~mL}$ of $0.25 \%$ bupivacaine was injected in this fascial plane (Figure $2 \mathrm{C}$ and $\mathrm{D}$ ). The patients were observed for 15 min after performing the block. The sensory level of the block was evaluated the loss of sensation over T2-6 dermatomes by pinprick test with the comparison of the opposite side. In the pinprick test, a sharp object such as a needle is applied gently to certain dermatome areas on the skin and the patient is asked to describe this feeling. All Pecs II block procedures were performed by an anesthesiologist who was experienced in ultrasound-guided nerve blocks.

\section{LA Group}

The skin puncture site was anesthetized with a $25 \mathrm{G}$ needle in both groups by injecting $2 \%$ lidocaine (Figure $3 \mathrm{~A}$ ). The skin and the deep tissue infiltration of the targeted area of the anterior chest wall were performed with a total of $25 \mathrm{~mL}$ of $0.25 \%$ bupivacaine (Figure 3B).

The patients were followed up in the post-anesthesia care unit (PACU) for 2 hours at the end of the implantation procedure. Pain intensity was measured using VAS in 


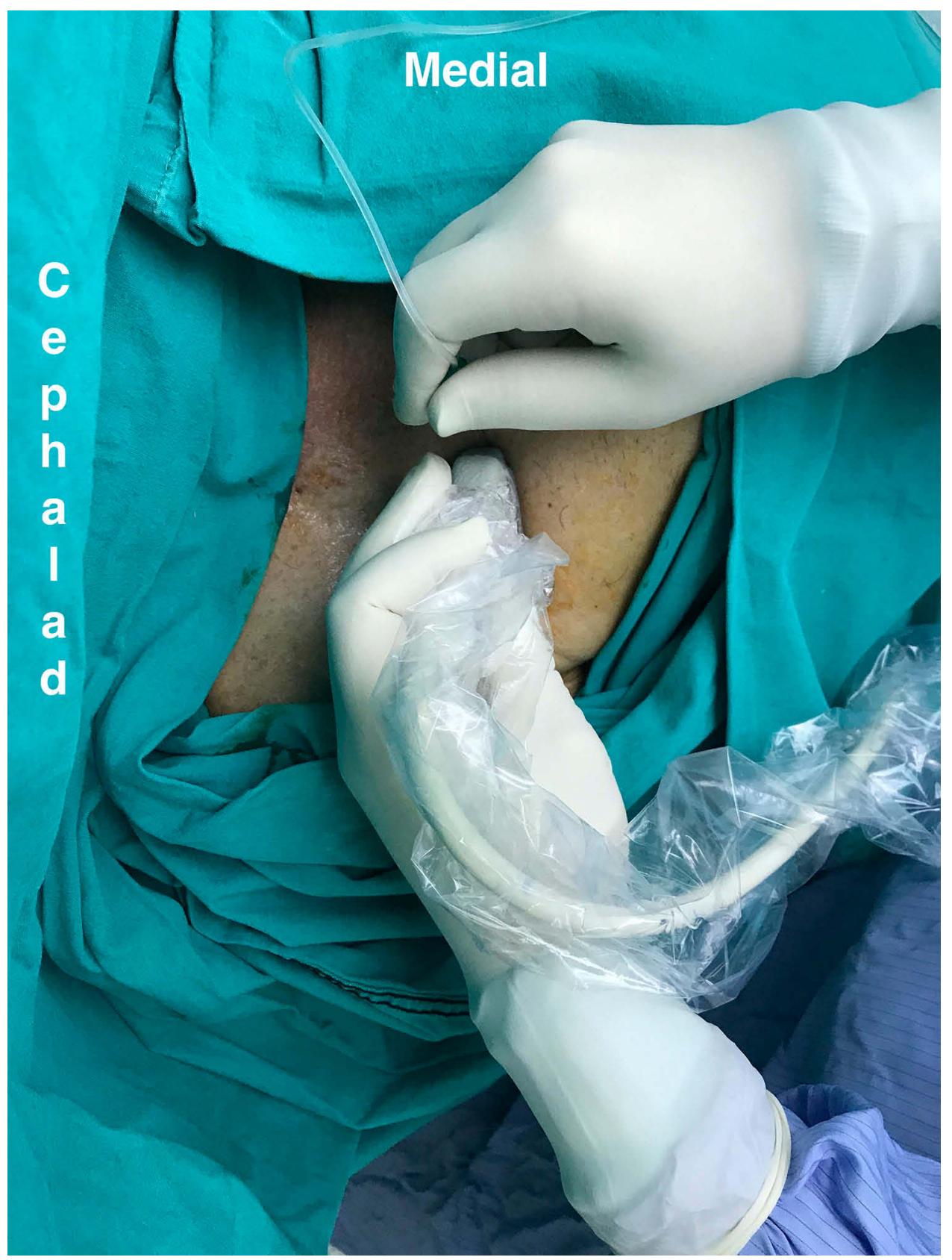

Figure I The position of ultrasound probe and needle in ultrasound-guided Pecs II block procedure.

the second hour. In the case of insufficient analgesia (VAS $>4$ ), $0.05 \mathrm{mcg}$ fentanyl was administered as a rescue analgesic in PACU. Patients were advised to use $25 \mathrm{mg}$ dexketoprofen orally as a non-steroidal anti-inflammatory drug (NSAID) if they felt pain after discharge in the first 24 hours. All procedural parameters including demographics of the patients, postoperative supplemental opioid requirement, both post-procedural pain scores at 2nd and 24th hours, and total NSAID consumption in the first 24 hours were recorded.

\section{Statistical Analysis}

The data obtained from the study were analyzed using the Statistical Package for Social Sciences version 21.0 (SPSS Inc., Chicago, IL, USA). Data were expressed as numbers, percentages, and mean \pm standard deviation. The normality of the data was examined using the KolmogorovSmirnov test. The Student's $t$-test was used to compare normally distributed numerical data for independent samples. Chi-square and Fisher's exact tests were used to 


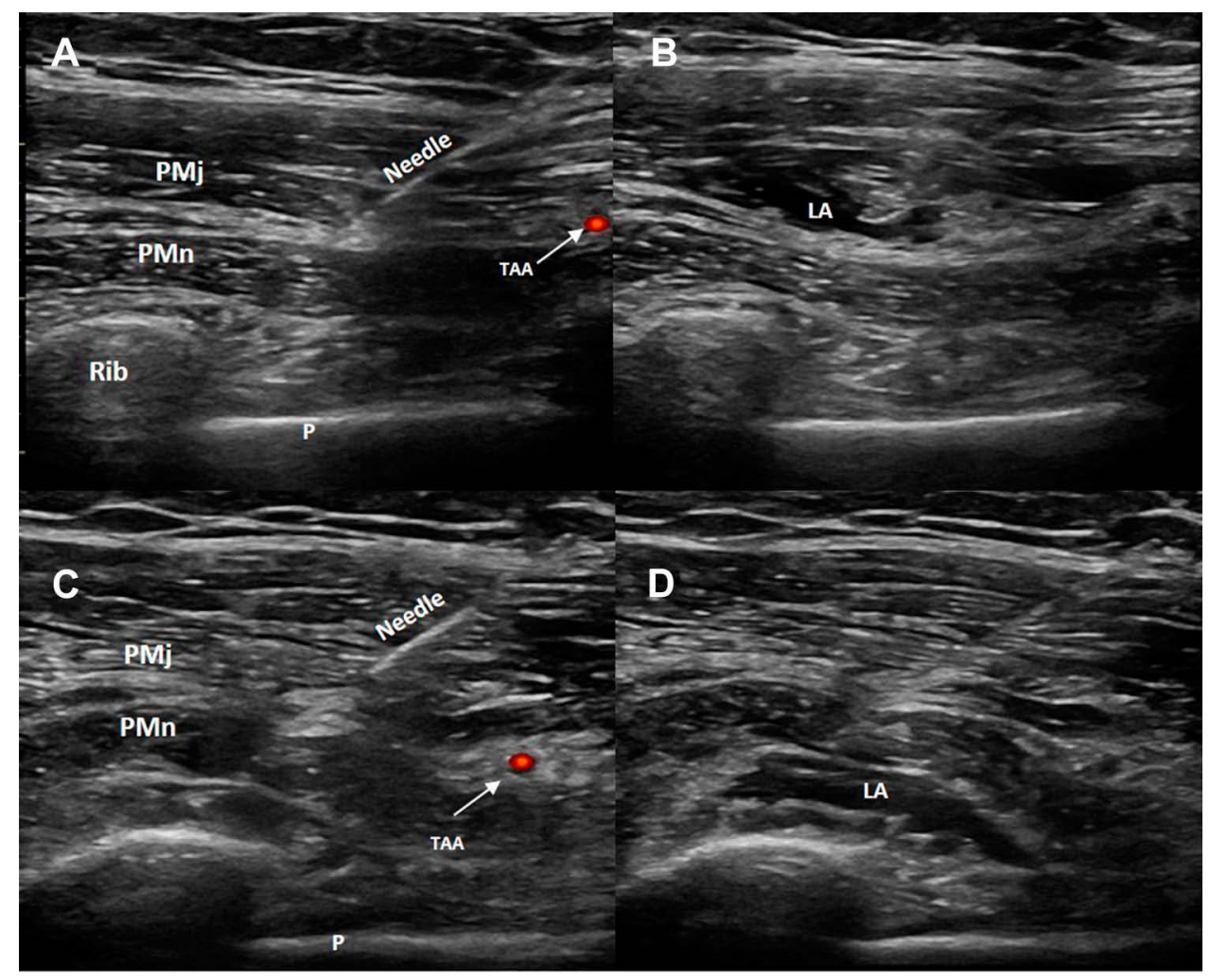

Figure 2 (A) Sonogram of the needle placement for Pecs I block (first injection of Pecs II block). (B) Local anesthetic spread into the fascial plane between the pectoralis major and minor muscles. (C) Sonogram of the needle placement for second injection of Pecs II block. (D) Local anesthetic spread into the fascial plane between pectoralis minor and serratus anterior muscles.

Abbreviations: PMj, pectoralis major muscle; PMn, pectoralis minor muscle; TAA, pectoral branch of the thoracoacromial artery; P, pleura; LA, local anesthetic.

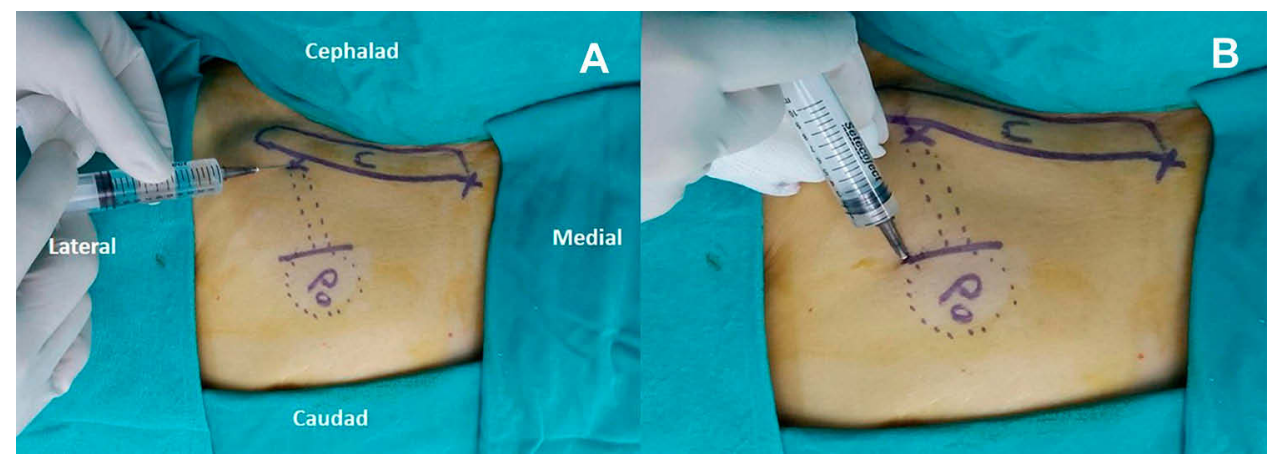

Figure 3 (A) Local anesthetic injection to the needle puncture site. (B) Skin and deep tissue infiltration of the port chamber insertion site. Abbreviations: $\mathrm{C}$, clavicle; Po, port chamber insertion site.

compare categorical variables. A p-value $<0.05$ was considered statistically significant.

\section{Results}

During the study period, although 260 patients had CVPC placement, 187 patients were included in the study. Twenty-five patients did not meet the inclusion criteria, and 48 patients had missing follow-up data. The remaining 84 patients were included in the Pecs group and 103 patients in the LA group. The demographic characteristics of the patients and their etiological diseases for CVPC application are summarized in Table 1. Statistical analysis showed no significant differences between the two groups in terms of age, weight, height, BMI, and gender.

The postoperative 2nd hour VAS scores were similar in both groups and were lower than the 24th hour VAS scores. VAS scores at the 24th hours in the Pecs group were significantly lower than the LA group $(\mathrm{P}=0.001)$. While the 
Table I Demographic Characteristics and Indications for Port Catheter Implantation of the Study Population

\begin{tabular}{|c|c|c|c|c|}
\hline & & $\begin{array}{l}\text { Pecs Group } \\
(n=84)\end{array}$ & $\begin{array}{l}\text { LA Group } \\
(n=103)\end{array}$ & $\mathbf{p}$ \\
\hline \multicolumn{2}{|c|}{ Age (years) } & $55.4 \pm 13.6$ & $56 \pm 13.7$ & $0.75^{*}$ \\
\hline \multicolumn{2}{|c|}{ Weight (kg) } & $68.5 \pm 8.2$ & $68.5 \pm 8.4$ & $0.99 *$ \\
\hline \multicolumn{2}{|c|}{ Height $(\mathrm{cm})$} & $165.4 \pm 7.6$ & $165.2 \pm 7.4$ & $0.36 *$ \\
\hline \multicolumn{2}{|c|}{ BMI $\left(\mathrm{kg} / \mathrm{m}^{2}\right)$} & $25.2 \pm 3.6$ & $24.9 \pm 4.4$ & $0.57^{*}$ \\
\hline \multirow[t]{2}{*}{ Gender } & Female, n (\%) & $34(40.5)$ & $37(35.9)$ & $0.54 * *$ \\
\hline & Male, n (\%) & $50(59.5)$ & $66(64.1)$ & \\
\hline \multicolumn{2}{|c|}{ Colon cancer } & $36(42.9 \%)$ & $34(33 \%)$ & \\
\hline \multicolumn{2}{|c|}{ Gastric cancer } & $9(10.7 \%)$ & $28(27.2 \%)$ & \\
\hline \multirow{2}{*}{\multicolumn{2}{|c|}{$\begin{array}{l}\text { Esophageal/pancreatic/ } \\
\text { liver/cholangiocarcinoma }\end{array}$}} & $10(12 \%)$ & $12(\mid 1.7 \%)$ & \\
\hline & & & & \\
\hline \multicolumn{2}{|c|}{ Leukemia/lymphoma } & $10(12 \%)$ & $6(5.8 \%)$ & \\
\hline \multicolumn{2}{|c|}{ Breast cancer } & $3(3.5 \%)$ & $6(5.8 \%)$ & \\
\hline \multicolumn{2}{|c|}{ Lung cancer } & $5(5.9 \%)$ & $4(3.9 \%)$ & \\
\hline \multicolumn{2}{|c|}{$\begin{array}{l}\text { Genitourinary tract cancer } \\
\text { (ovary, uterus, prostate, } \\
\text { testis) }\end{array}$} & $6(7.1 \%)$ & $4(3.9 \%)$ & \\
\hline \multicolumn{2}{|c|}{ Other } & $5(5.9 \%)$ & $9(8.7 \%)$ & \\
\hline \multicolumn{2}{|l|}{ Total } & $84(100)$ & $103(100)$ & \\
\hline
\end{tabular}

Notes: *Student's $t$-test; ** Fisher's test.

number of fentanyl rescue doses administered in PACU was similar, the total NSAID consumption in the first 24 hours was higher in the LA group than in the Pecs group $(\mathrm{p}=0.01)$ (Table 2).

In the Pecs group, one in four patients required NSAID at least once in the first 24 hours, while more than half of the patients in the LA group had this requirement $(p=0.006)$.

Table 2 VAS Scores at 2nd and 24th Hours

\begin{tabular}{|c|c|c|c|c|}
\hline & & $\begin{array}{l}\text { Pecs } \\
\text { Group } \\
(n=84)\end{array}$ & $\begin{array}{l}\text { LA } \\
\text { Group } \\
(n=103)\end{array}$ & $\mathbf{p}$ \\
\hline \multicolumn{2}{|l|}{ VAS 2nd hour } & $I . I \pm I . I$ & $1.2 \pm 1.1$ & 0.73 \\
\hline \multicolumn{2}{|l|}{ VAS 24 th hour } & $1.6 \pm 1.6$ & $3.2 \pm 1.8$ & $<0.001$ \\
\hline \multicolumn{2}{|l|}{$\begin{array}{l}\text { Number of patient request } \\
\text { rescue fentanyl dose in } \\
\text { PACU }\end{array}$} & $12(14.3)$ & $16(15.5)$ & 0.64 \\
\hline \multicolumn{2}{|l|}{$\begin{array}{l}\text { Number of patients } \\
\text { requiring NSAID at least } \\
\text { once in the first } 24 \text { hours }\end{array}$} & $21(25)$ & $46(44.7)$ & 0.006 \\
\hline \multirow[t]{3}{*}{ Number of NSAID dose } & I & $16(19)$ & $28(27)$ & \\
\hline & 2 & $5(6)$ & $13(12.6)$ & \\
\hline & 3 & 0 & $5(4.9)$ & \\
\hline
\end{tabular}

Notes: The number of rescue doses of fentanyl applied in PACU and total NSAID consumption in the first 24 hours.
Five patients in the Pecs group and 18 in the LA group needed NSAID more than twice in the first 24 hours. Moreover, none of the patients in the Pecs group needed NSAID three times (Table 2).

\section{Discussion}

In this study, postoperative analgesic effects of ultrasoundguided Pecs II block and infiltration of LA were compared in CVPC implantation procedures. Even though there was no obvious difference in the first 2 hours postoperatively, ultrasound-guided Pecs II block significantly reduced VAS scores, and total NSAID consumption in the first 24 hours according to the LA group.

CVPC implantation is a common procedure performed in cancer patients since the beginning of their treatment protocols. Light sedation and LA infiltration is the most common anesthetic approach for this procedure. ${ }^{7,8}$ Even though there is no report providing evidence of the degree of postoperative pain associated with CVPC implantation, it is obvious that it should be managed well in cancer patients who are prone to development of chronic pain. ${ }^{9,10}$

LA infiltration is widely used for postoperative analgesia in surgeries of the upper chest, such as breast surgery, implantation of chest drains, pacemakers, and CVPCs. ${ }^{11,12}$ Postoperative pain management is underestimated in patients undergoing pacemaker and CVPC placement who are sensitive to opioid use and are more fragile due to comorbid diseases. Furthermore, Biocic et al ${ }^{13}$ stated that only $31 \%$ of the patients were administered analgesics for postoperative pain management after ICD implantation. Maurer et $\mathrm{al}^{14}$ suggested that LA infiltration provides sufficient analgesia for CVPC placement. In contrast, Byager et $\mathrm{al}^{11}$ revealed that infiltration of the incision site with local anesthetics has a mild analgesic effect within the first few hours postoperatively. Accordingly, we did not observe significant differences in pain scores between the groups within the first 2 hours after CVPC implantation. However, in the remainder of the first 24 hours after surgery, we observed that most patients in the LA group needed rescue analgesia, which reflects the inefficiency of local anesthetic infiltration.

There are studies on various regional anesthesia techniques and nerve blocks performed to provide longer postoperative analgesia than LA infiltration. ${ }^{15-18}$ Ultrasound-guided Pecs II block was used for this purpose in prolonging analgesia in surgical interventions of the anterior chest wall. ${ }^{19,20}$ Accordingly, in our study, VAS scores and analgesic consumption of patients in the first 24 hours were significantly lower in 
the Pecs group. In Pecs II block, local anesthetic solution accumulates in the facial plane; therefore, it does not spread around while the packet for port's chamber was created. However, since local anesthesia is drained at this stage, the duration of analgesia may be shortened in those who underwent LA infiltration.

Ultrasound-guided regional anesthesia techniques are more reliable and more effective than blind or landmarkbased approaches. ${ }^{21}$ However, during these procedures, it is vitally important to have good anatomy knowledge and experience about nerve blocks under ultrasound guidance. $^{22}$ In the study, the physicians who applied the blocks had experience on the procedure and no complication was observed in any of the patients.

There were some limitations in the study, and the first was that the study had a retrospective design. Another limitation was that a more objective result could be obtained by using patient-controlled analgesia device instead of oral NSAID in the evaluation of postprocedure analgesic use. To our knowledge, this is one of the few studies on the use of ultrasound-guided Pecs II on pain management after CPVC implantation and will contribute to the literature. Prospective randomized controlled studies are needed on the subject.

\section{Conclusion}

Ultrasound-guided Pecs II block is an effective method that reduces postoperative NSAID consumption and provides better postoperative pain management when compared to LA infiltration in CVPC implanted patients. Thus, ultrasound-guided Pecs II block can be used safely for postoperative analgesia in CVPC implantation procedures.

\section{Disclosure}

This research did not receive any specific grant from funding agencies in the public, commercial, or not-for-profit sectors and the authors report no conflicts of interest in this work.

\section{References}

1. Rosen J, Lawrence R, Bouchard M, Doros G, Gardiner P, Saper R. Massage for perioperative pain and anxiety in placement of vascular access devices. Adv Mind Body Med. 2013;27:12-23.

2. Munshey F, Ramamurthi RJ, Tsui B. Early experience with PECS 1 block for Port-a-Cath insertion or removal in children at a single institution. J Clin Anesth. 2018;49:63-64. doi:10.1016/j.jclinane. 2018.06.010

3. Berlin G, Enerbäck L. Changes in numbers and heparin content of peritoneal fluid mast cells of growing rats measured by flow cytofluorometry. J Histochem Cytochem. 1978;26:14-21. doi:10. $1177 / 26.1 .621375$
4. Blanco R. The 'pecs block': a novel technique for providing analgesia after breast surgery. Anaesthesia. 2011;66:847-848. doi:10.1111/ j.1365-2044.2011.06838.x

5. Blanco R, Fajardo M, Parras Maldonado T. Ultrasound description of Pecs II (modified Pecs I): a novel approach to breast surgery. Rev Esp Anestesiol Reanim. 2012;59(9):470-475. doi:10.1016/j.redar.2012. 07.003

6. Porzionato A, Macchi V, Stecco C, Loukas M, Tubbs RS, De Caro R. Surgical anatomy of the pectoral nerves and the pectoral musculature. Clin Anat. 2012;25(5):559-575. doi:10.1002/ca.21301

7. Haslam PJ, Yap B, Mueller PR, Lee MJ. Anesthesia practice and clinical trends in interventional radiology: a European survey. Cardiovasc Intervent Radiol. 2000;23(4):256-261. doi:10.1007/ s002700010065

8. Mueller PR, Wittenberg KH, Kaufman JA, Lee MJ. Patterns of anesthesia and nursing care for interventional radiology procedures: a national survey of physician practices and preferences. Radiology. 1997;202:339-343. doi:10.1148/radiology.202.2.9015053

9. Sansone P, Pace MC, Passavanti MB, Pota V, Colella U, Aurilio C. Epidemiology and incidence of acute and chronic Post-Surgical pain. Ann Ital Chir. 2015;86(4):285-292.

10. Wang L, Guyatt GH, Kennedy SA, et al. Predictors of persistent pain after breast cancer surgery: a systematic review and meta-analysis of observational studies. CMAJ. 2016;4(188):E352-E361. doi:10.1503/ cmaj. 151276

11. Byager N, Hansen MS, Mathiesen O, Dahl JB. The analgesic effect of wound infiltration with local anaesthetics after breast surgery: a qualitative systematic review. Acta Anaesthesiol Scand. 2014;58:402-410. doi:10.1111/aas.12287

12. Kaya E, Südkamp H, Lortz J, Rassaf T, Jánosi RA. Feasibility and safety of using local anaesthesia with conscious sedation during complex cardiac implantable electronic device procedures. Sci Rep. 2018;8(1):7103. doi:10.1038/s41598-018-25457-x

13. Biocic M, Vidosevic D, Boric M, et al. Anesthesia and perioperative pain management during cardiac electronic device implantation. J Pain Res. 2017;10:927-932. doi:10.2147/JPR.S132241

14. Maurer MH, Beck A, Hamm B, Gebauer B. Central venous port catheters: evaluation of patients' satisfaction with implantation under local anesthesia. J Vasc Access. 2009;10:27-32. doi:10.1177/ 112972980901000105

15. Calì Cassi L, Biffoli F, Francesconi D, Petrella G, Buonomo O. Anesthesia and analgesia in breast surgery: the benefits of peripheral nerve block. Eur Rev Med Pharmacol Sci. 2017;21(6):1341-1345.

16. Woodworth GE, Ivie RMJ, Nelson SM, Walker CM, Maniker RB. Perioperative breast analgesia: a qualitative review of anatomy and regional techniques. Reg Anesth Pain Med. 2017;42:609-631. doi:10.1097/AAP.0000000000000641

17. Oksuz G, Bilgen F, Arslan M, Duman Y, Urfalıglu A, Bilal B. Ultrasound-guided bilateral erector spinae block versus tumescent anesthesia for postoperative analgesia in patients undergoing reduction mammoplasty: a randomized controlled study. Aesthetic Plast Surg. 2019;43:291-296. doi:10.1007/s00266-018-1286-8

18. Sato M, Shirakami G, Fukuda K. Comparison of general anesthesia and monitored anesthesia care in patients undergoing breast cancer surgery using a combination of ultrasound-guided thoracic paravertebral block and local infiltration anesthesia: a retrospective study. J Anesth. 2016;30:244-251. doi:10.1007/s00540-015-2111-z

19. Kamiya Y, Hasegawa M, Yoshida T, Takamatsu M, Koyama Y. Impact of pectoral nerve block on postoperative pain and quality of recovery in patients undergoing breast cancer surgery: a randomised controlled trial. Eur $J$ Anaesthesiol. 2018;35(3):215-223. doi:10.1097/EJA.0000000000000762

20. Kulhari S, Bharti N, Bala I, Arora S, Singh G. Efficacy of pectoral nerve block versus thoracic paravertebral block for postoperative analgesia after radical mastectomy: a randomized controlled trial. Br J Anaesth. 2016;117(3):382-386. doi:10.1093/bja/aew223 
21. McDermott G, Korba E, Mata U, et al. Should we stop doing blind transversus abdominis plane blocks? Br J Anaesth. 2012;108 (3):499-502. doi:10.1093/bja/aer422
22. Wilson JM, Germain G, Vaghadia H, Tang R, Sawka A. In-plane ultrasound-guided needle insertion ALONG or ACROSS the visual axis hand positions. Br J Anaesth. 2014;113(4):717-8. doi:10.1093/bja/aeu324

\section{Publish your work in this journal}

The Journal of Pain Research is an international, peer reviewed, open access, online journal that welcomes laboratory and clinical findings in the fields of pain research and the prevention and management of pain. Original research, reviews, symposium reports, hypothesis formation and commentaries are all considered for publication. The manuscript

Submit your manuscript here: https://www.dovepress.com/journal-of-pain-research-journa management system is completely online and includes a very quick and fair peer-review system, which is all easy to use. Visit http:// www.dovepress.com/testimonials.php to read real quotes from published authors. 